\title{
DISPENSA DE LICENCIAMENTO AMBIENTAL PARA ATIVIDADES RURAIS NO ESTADO DO TOCANTINS: SUPORTE TEÓRICO PARA UM DISCURSO ARGUMENTATIVO
}

\author{
Spencer Vampré \\ Mestre em Prestação Jurisdicional e Direitos Humanos pela Universidade Federal do \\ Tocantins, em parceria com a Escola Superior da Magistratura Tocantinense (UFT/ESMAT). \\ Especialista em Teoria da Decisão Judicial pela ESMAT. Especialista em Direito Consti- \\ tucional pela Universidade do Tocantins (UNITINS). Extensão universitária em Gestão do \\ Poder Judiciário pela Faculdade Educacional da LAPA (FAEL). Graduado em Direito pela \\ Pontifícia Universidade Católica de Campinas/SP (PUC-Campinas). Instrutor no Programa \\ de Pós-Graduação (especialização) em Prática Judiciária (ESMAT). Tutor no Programa de \\ Pós-Graduação (especialização) em Teoria da Decisão Judicial (ESMAT). \\ E-mail: spencervampre@yahoo.com.br
}

Patrícia Medina

Doutora em Educação pela Universidade Federal de Goiás (UFG). Mestre em Educação pela Pontifícia Universidade Católica do Rio Grande do Sul (PUC-RS). Graduada em Direito pela Fundação Universidade Federal do Tocantins (UFT). Graduação em Pedagogia pela Faculdade Porto-Alegrense de Educação Ciências Humanas e Letras (FAPA). Docente do Mestrado em Prestação Jurisdicional em Direitos Humanos da Escola Superior da Magistratura Tocantinense (ESMAT), em cooperação com a Universidade Federal do Tocantins (UFT). Professora adjunta IV da UFT. Coordenadora do curso de Pedagogia da UFT. E-mail: patriciamedina@mail.uft.edu.br

\section{RESUMO}

Trata-se de resultado de pesquisa descritiva, que objetivou oferecer suporte teórico e argumentação jurídica para futuras decisões judiciais, a partir da alteração legislativa promovida pela Lei $\mathrm{n}^{0} 2.713 / 13$, de 9 de maio de 2013, no âmbito do Estado do Tocantins, que promoveu a dispensa de licenciamento ambiental para o exercício de atividades agrossilvipastoris, na contramão da histórica evolução do tratamento conferido ao tema. $\mathrm{O}$ artigo foi construído a partir de coleta de dados próprios da pesquisa bibliográfica, apresentados a partir de cronologia histórica, mediante constatação de que os temas relacionados ao meio ambiente sempre rondaram a pauta político-administrativa brasileira, desde a Colônia. No período republicano, vieram as primeiras codificações ambientais nacionais, a adesão às convenções internacionais e a instituição da Política Nacional do Meio Ambiente, pavimentando o caminho para a atual realidade brasileira, de ampla proteção constitucional ao equilíbrio ecológico. Entretanto, algumas políticas públicas locais ainda se contrapõem a esse contexto histórico, como a ocorrida com a entrada em vigor da referida Lei Estadual, submetida à análise, neste trabalho, sob os 
enfoques argumentativos constitucional, ético e do direito penal, essenciais para o enfrentamento judicial da dispensa de licenciamento ambiental por ela introduzida. Resultou demonstrado que dispensar o licenciamento ambiental configura perigoso retrocesso ofensivo aos deveres de prevenção e ao dever de equidade intergeracional. A legislação em análise não resistiu às diretrizes argumentativas para enfrentamento judicial nos enfoques das ciências ambientais, constitucional formal e material, ético e do direito penal.

Palavras-chave: proteção ambiental; políticas públicas; argumentação jurídica.

\section{DISPENSE OF ENVIRONMENTAL LICENSING FOR RURAL ACTIVITIES IN THE STATE OF TOCANTINS: THEORETICAL SUPPORT FOR AN ARGUMENTATIVE DISCOURSE}

\section{ABSTRACT}

This work is a result of a descriptive research, which aimed to provide theoretical support and legal arguments for judicial decisions, based on the legislative amendment promoted by Law $n^{\circ} 2.713 / 13$, of the State of Tocantins, which promoted the exemption of environmental licensing for the exercise of agroforestry activities, contrary to the historical evolution of the treatment given to the theme. The article was constructed based on the collection of data from the bibliographic research, based on historical chronology, through the observation that the themes related to the environment have always been around the Brazilian politicaladministrative agenda, since the Colony. In the Republican period, the first national environmental codifications, the adherence to international conventions and the institution of the National Environmental Policy made the way for the current Brazilian reality of constitutional protection to the ecological balance. However, some local public policies still contradicting this historical context, such as that occurred with the Law submitted to the analysis, under the constitutional, ethical, and criminal law argumentative approaches. The legislation in question did not stand up to the argumentative guidelines for judicial confrontation in environmental, formal and material constitutional, ethical and criminal law approaches.

Keywords: environmental protection; public policy; legal arguments. 


\section{INTRODUÇÃO}

O desenvolvimento nacional encontra-se estabelecido constitucionalmente como um dos objetivos fundamentais da República Federativa do Brasil, juntamente com as metas de construção de uma sociedade livre, justa e solidária, erradicação da pobreza e promoção do bem de todos, indistintamente (Constituição da República Federativa do Brasil, art. $3^{\circ}$, II).

A atividade econômica exerce, no contexto desenvolvimentista, papel fundamental. Constitui, em verdade, o alicerce do desenvolvimento. Pautada na finalidade de assegurar existência digna a todos, a ordem econômica deve, por preceito constitucional (art. 170), observar determinados princípios, dentre os quais interessa destacar, neste estudo, o de defesa do equilíbrio ecológico do meio ambiente, bem de uso comum do povo, essencial à sadia qualidade de vida (art. 225), mediante tratamento diferenciado, conforme o impacto ambiental dos produtos e serviços e de seus processos de elaboração e prestação (art. 170, VI).

As ciências do meio ambiente afirmam que a Terra apresenta um sistema de regulação global, fruto do delicado inter-relacionamento entre os ecossistemas, responsável pelo equilíbrio ecológico do planeta. Disso resulta que determinadas alterações no ambiente natural impactam o sistema ecológico local e podem, em última análise, afetar o equilíbrio global. Desse modo, seja por influência do conhecimento científico, seja por dever de obediência aos preceitos constitucionais, não há dúvidas de que o desenvolvimento econômico deve caminhar pari passu à preservação ambiental.

É dever geral, portanto - mesmo por parte daqueles que se contrapõem às teses científicas de que o equilíbrio planetário se encontra irreversivelmente lesionado - a consolidação da consciência de que a afetação dos ecossistemas acarreta riscos aos bens maiores da vida humana, tais como saúde, qualidade de vida e bem estar, os quais também contam com especial proteção constitucional.

Nesse cenário, a gestão pública assume sobrelevada relevância. Atento à necessidade de preservação do equilíbrio ecológico regional e, em última análise, global, o presente estudo pretende oferecer suporte teórico e argumentação jurídica para tomada de decisões acerca da alteração do Programa de Adequação Ambiental de Propriedades e Atividades Rurais do Estado do Tocantins, ocorrida com a entrada em vigor da Lei Estadual $n^{\circ}$ 
2.713, de 9 de maio de 2013, a qual dispensou de licenciamento ambiental as atividades agrossilvipastoris desenvolvidas no território tocantinense.

Acredita-se que referida medida político-legislativa não resistirá, caso venha a ser questionada judicialmente, à argumentação jurídica amparada nos preceitos da ética, do direito penal e da ordem constitucional brasileira. É o que se pretende demonstrar com o presente estudo.

A pesquisa que deu origem a este artigo pode ser classificada como pesquisa aplicada, uma vez que objetiva gerar conhecimentos para aplicação prática, dirigidos à solução de um problema específico, qual seja, a recente dispensa de licenciamento ambiental no Tocantins resiste à argumentação jurídica baseada na ética, no direito penal e na ordem constitucional brasileira?

Do ponto de vista da abordagem do problema, trata-se de pesquisa qualitativa, especialmente porque visa à interpretação do fenômeno e atribuição de significados, sem demandar métodos ou técnicas estatísticas. Do ponto de vista dos objetivos, é exploratório-descritiva, com procedimentos próprios da pesquisa bibliográfica, elaborada a partir de material já publicado na rede mundial de computadores, periódicos, legislações e, principalmente, em livros. Para tanto o escrito foi organizado em três seções. A primeira recompõe a cronologia histórica das principais questões ambientais no Brasil a partir do ordenamento jurídico; em seguida ganha enfoque especial a legislação tocantinense objeto de análise e finalmente são apresentadas as diretrizes jurídicas para o enfrentamento da questão a partir da teoria da argumentação.

\section{DESENHO HISTÓRICO DAS QUESTÕES AMBIENTAIS NO BRASIL}

Registram-se danos ambientais no Brasil desde o tempo da colonização portuguesa, a partir de quando o território brasileiro passou a ser explorado economicamente. Estudos antropológicos revelam que as populações nativas viviam, cada qual ao seu modo, integradas à natureza, até que o interesse português na madeira para construção de naus, o estabelecimento da indústria do "ouro branco" (cultivo de cana-de-açúcar e implantação de engenhos) e a exploração de minérios, deram início, não somente às grandes alterações no ambiente natural - início do Século XVI (CARRILLO, 2003) - mas também à instituição das primeiras regras de direito ambiental (LAPA, 2000). A atividade econômica dominante, por 
si, acarretava dano à natureza. Relatos históricos dão conta de frequentes incêndios florestais ocasionados por combustão espontânea do álcool evaporado dos engenhos de açúcar (CARRILLO, 2003, p. 61). Registrase que José Bonifácio Andrade e Silva voltou-se contra a agricultura escravista brasileira e o uso de tecnologias rudimentares que acabariam por transformar nosso país em deserto como o da Líbia, fornecedora de grãos para Portugal durante séculos (MEDINA, P., 2011).

$\mathrm{O}$ pioneiro arcabouço legislativo de então inspirou as primeiras regras ambientais da Colônia. Com amparo nas Ordenações Afonsinas (Online, 2018), em Portugal existia, desde 1393, proibição ao corte de árvores frutíferas.

Nessa vertente, instituíram-se em solo brasileiro, no início da colonização, as primeiras normas reguladoras da exploração dos recursos naturais, motivadas, logicamente, pelo desenvolvimento econômico e pela preocupação da Coroa Portuguesa com exploração clandestina de bens naturais (MAGALHÃES, 2002). Datam desse período as primeiras exigências de licenciamento para exploração de recursos naturais. Segundo Magalhães (2002), o arcabouço contava com restrições à caça e repetia a tipificação penal portuguesa para o corte de árvores, com pena definida de acordo com espécie vegetal. Instituiu-se, desde então, controle à exploração madeireira, com sanções variadas de pena pecuniária até açoite, degredo e pena de morte. (MENDONÇA, 1972).

Ainda no tempo do Império, outras iniciativas revelavam atos de governo atrelados à preocupação com a questão ambiental, embora ainda essencialmente associados ao viés econômico. Em 1861, por ordem de Dom Pedro II, deu-se início à recuperação da Mata Atlântica, gravemente afetada pelas lavouras de café, motivo de severa escassez de água na cidade do Rio de Janeiro (BEYRUTH, 2006).

Durante o período republicano, a partir da década de 1930, notase a crescente preocupação da administração pública brasileira com a exploração dos recursos naturais. Temas específicos passaram a ser codificados: florestas, águas, mineração e caça. Criaram-se as primeiras unidades de conservação ambiental. Estudos sobre Ecologia foram inseridos no meio acadêmico. Em semelhante compasso, no âmbito internacional, pós-segunda guerra, as ciências do ambiente também ganhavam relevo, com a União Internacional para a Conservação da Natureza na Suíça, em 1947.

Em 1958, criou-se no Brasil a Fundação Brasileira para Conservação 
da Natureza, todavia, o desenvolvimento econômico permaneceu assentado na ampla exploração de recursos naturais. Nas décadas seguintes, 1960, 1970, qualidade de vida e escassez de recursos começaram a emitir visíveis sinais de alerta, especialmente pela redução do volume de água potável e pela poluição atmosférica, fatores que, somados ao crescimento populacional, ampliaram a conscientização acerca da necessidade de preservação, com a agregação da comunidade científica a movimentos sociais internacionais, tais como o World Wide Fund for Nature ${ }^{l}$ (WWF) em 1961 na Suíça e o Greenpeace, no Canadá em 1971.

Concomitantemente, a legislação nacional seguiu avançando com a edição de diplomas importantes: a Lei $\mathrm{n}^{\circ} 4.504$, de 30 de novembro de 1964 (Estatuto da Terra); Lei n ${ }^{\circ}$ 4.771, de 15 de setembro de 1965 (Código Florestal); Lei $n^{\circ}$ 5.197, de 3 de janeiro de 1967 (Proteção à Fauna); Decreto-lei no 221 (Códigos de Pesca) e Decreto-lei no 227 (Mineração) e criação do Instituto Brasileiro de Desenvolvimento Florestal pelo Decretolei $\mathrm{n}^{\mathrm{o}} 289$, todos de 28 de fevereiro de 1967.

Na esteira da Conferência das Nações Unidas para o Meio Ambiente em Estocolmo, 1972 e da publicação, no mesmo ano, do relatório do Clube de Roma sob o título Os limites do Crescimento, amparado na conclusão de cientistas do Massachusetts Institute of Technology (MIT), segundo a qual o Planeta Terra não suportaria o crescimento populacional no ritmo de então, a administração pública brasileira avança, criando a Secretaria Especial do Meio Ambiente pelo Decreto $n^{\circ} 73.030$, de 30 de outubro de 1973, vinculada ao Governo Federal. O órgão tinha como objetivo regular e fiscalizar a exploração racional dos recursos e a preservação ambiental. Reforça-se, assim, passo a passo, o entrelaçamento entre políticas públicas e questões ecológicas.

Nova ferramenta de proteção ambiental, com diretrizes oficiais de desenvolvimento sustentável, entra em vigor, em 1981, a Lei no 6.938/81, de 31 de agosto de 1981, que dispõe sobre a Política Nacional do Meio Ambiente, seus fins e mecanismos de formulação e aplicação. Após longa maturação, o tema alcançou patamar constitucional em 1988, positivandose, na ordem jurídica, o direito ao meio ambiente equilibrado, bem comum de uso do povo e essencial à sadia qualidade de vida, impondo-se expressamente, ao Poder Público e à coletividade, sua defesa e preservação para as presentes e futuras gerações.

A preocupação com a ocupação e uso da terra não é novidade no

1 Fundo Mundial para a Natureza 
Brasil. Permeou todo o desenvolvimento nacional desde a Colônia até os dias atuais. Entretanto, somente o avançado lineamento legislativo, hoje alicerçado em uma pioneira tutela ambiental constitucional, não vem se mostrando suficiente para conter a perigosa devastação da natureza, verdadeiramente desenfreada no Brasil. Nalini salienta que

[...] se deve reagir à sanha devastadora que já conseguiu fazer da Mata Atlântica uma amostragem quase insignificante da exuberância verde aqui encontrada pelos descobridores e que os fizeram acreditar que a Terra de Santa Cruz já fora o Paraíso Terreal. Sanha devastadora que vai converter em breve a Floresta Amazônica - a última grande floresta tropical do mundo - numa zona desertificada, pobre e imprópria a caracterizar o sonho do desenvolvimento sustentável. (NALINI 2008, p. 366).

Tornou-se imperiosa, então, a efetiva proteção ecológica, como condição essencial à continuidade da exploração dos recursos naturais, revelando-se indispensável a premissa administrativa de desenvolvimento sustentável, conforme pontuou o Supremo Tribunal Federal:

O princípio do desenvolvimento sustentável, além de impregnado de caráter eminentemente constitucional, encontra suporte legitimador em compromissos internacionais assumidos pelo Estado brasileiro e representa fator de obtenção do justo equilíbrio entre as exigências da economia e as da ecologia, subordinada, no entanto, a invocação desse postulado, quando ocorrente situação de conflito entre valores constitucionais relevantes, a uma condição inafastável, cuja observância não comprometa nem esvazie o conteúdo essencial de um dos mais significativos direitos fundamentais: o direito à preservação do meio ambiente, que traduz bem de uso comum da generalidade das pessoas, a ser resguardado em favor das presentes e futuras gerações. (ADI 3540 MC, Rel. Min. CELSO DE MELLO, Tribunal Pleno, julgado em 01/09/2005, DJ 3/2/2006, p.14).

Nesse contexto legislativo, é inequívoca e historicamente presente na realidade brasileira a exigência de licenciamento ambiental para toda e qualquer atividade produtiva, vinculada aos órgãos de fiscalização e controle ambiental, sobretudo em atividades humanas que interferem no ambiente natural, guardem ou não relação com exploração econômica. 


\section{A REVOGAÇÃO DA NECESSIDADE DE LICENCIAMENTO AMBIENTAL NO ESTADO DO TOCANTINS}

Em 8 de julho de 2011 instituiu-se no Estado do Tocantins, unidade federativa com significante atividade agroindustrial diretamente relacionada ao uso e exploração de recursos naturais, o Programa de Adequação Ambiental de Propriedade e Atividade Rural, previsto na Lei no 2.476/11. A ação governamental teve por objetivo promover a regularização de imóveis rurais, mediante inserção no Sistema de Cadastramento Ambiental Rural (CAR) e no Licenciamento Ambiental Único (LAU).

Como forma de incentivar a regularização, o cadastro espontâneo dos imóveis, por seus proprietários, implicava anistia de autuações anteriores à publicação da lei, ocorridas por força de outros diplomas legais afetos a questões ambientais, entre eles as Leis Estaduais 261/91 e 771/95 e Lei Federal 9.605/98, de 12 de fevereiro de 1998, que dispõem sobre as sanções penais e administrativas derivadas de condutas e atividades lesivas ao meio ambiente. Acarretava, ainda, suspensão da cobrança de multas decorrentes de infrações.

Outras medidas essenciais à preservação ecológica foram estipuladas no programa, tais como identificação de atividades desenvolvidas nas áreas rurais; quantificação de ativo e passivo florestal; monitoramento de desmatamento ilegal; verificação do atendimento às normas ambientais em vigor; manutenção de reservas e áreas protegidas; definição de procedimentos e políticas para formação de corredores ecológicos.

Dentre as exigências previstas no programa, figurava a de obtenção do Licenciamento Ambiental Único, requisito à instalação e operação de atividades agrossilvipastoris, que compreende o manejo integrado, em uma mesma área, de cultura agrícola, forrageira, árvores e animais. $\mathrm{O}$ desenvolvimento sustentável, amparado na premissa de regularização e adequação ambiental, parecia nortear o programa estadual original.

Entretanto, cerca de dois anos após entrar em vigor, o programa foi substituído, em 9 de maio de 2013, pela Lei n 2.713/13, com substanciais alterações, notadamente no que diz respeito à revogação sumária da necessidade de licenciamento ambiental para o desenvolvimento de atividades agrossilvipastoris, nos seguintes termos: "Art. 10 São dispensadas do licenciamento ambiental as atividades agrossilvipastoris", olvidando a histórica exigência de licenciamento ambiental para instalação 
de atividades rurais aplicada em solo brasileiro desde o tempo colonial. A dispensa foi justificada por seus idealizadores como desentrave a burocracia, a qual prejudica investimentos e emperra o crescimento do Estado.

O processo de aprovação da nova lei, a despeito da magnitude do tema, foi surpreendentemente célere. $\mathrm{O}$ projeto foi apresentado em plenário, na Assembleia Legislativa, no dia 7 de maio de 2013 e aprovado por unanimidade no dia seguinte. Veicularam-se notícias ${ }^{2}$ de que Ministério Público Federal, entidades da União (IBAMA e INCRA) e organizações não-governamentais receberam cópia do projeto de lei sem o dispositivo da dispensa de licenciamento (artigo 10), incluído posteriormente pela Assembleia Legislativa no texto definitivo.

O fato gerou elaboração de relatório, pela Procuradoria Federal Especializada (PFE/IBAMA-TO), assinalando que a aprovação da lei implica dilatar os mecanismos de tutela de proteção difusa integral do meio ambiente, convergindo num viés desenvolvimentista insustentável. Deu azo, ainda, ao posicionamento da Procuradoria da República no Tocantins no sentido de que a lei contraria a Política Nacional do Meio Ambiente (Lei ${ }^{\circ}$ 6.938/81), culminando em representação de inconstitucionalidade perante o Supremo Tribunal Federal pela Ação Direta de Inconstitucionalidade $n^{\circ}$ 5312, ainda sem julgamento definitivo de mérito.

Integra a cena, por fim, o fato de a alteração legislativa ter ocorrido cerca de dois meses antes da deflagração de uma operação policial que trouxe ao conhecimento público a investigação oficial sobre um suposto esquema ilegal de venda de licenças ambientais pelo órgão de fiscalização estadual o Instituto Natureza do Tocantins (NATURATINS), a qual culminou na prisão cautelar de servidores do órgão ${ }^{3}$.

Como se verá adiante, do ponto de vista dos princípios da prevenção, precaução, responsabilidade e proibição de retrocesso, bases do desenvolvimento sustentável, o preceito contido no artigo 10 da Lei Estadual $n^{\circ} 2.713 / 13$ é motivo de preocupação, especialmente ante a fragilidade do bioma cerrado, predominante no território tocantinense.

\footnotetext{
$2 \mathrm{http}: / /$ ambientalistasemrede.org/para-fomentar-o-agronegocio-estado-derruba-a-necessidade-delicenciamento-ambiental/, acessado em 18/5/2018.

3 Veja detalhes nos seguintes endereços: http:/g1.globo.com/to/tocantins/noticia/2013/07/policiaprende-outro-acusado-de-fraudar-licencas-ambientais.html; http://www.redeto.com.br/noticia-3391-operacao-para-desmantelar-quadrilha-que-agia-no-naturatinscumpre-sete-mandados-de-prisao.html\#.V3gDdPkrJGo;

http://www.t1 noticias.com.br/plantao-de-policia/policia-prende-3\%BA-servidor-do-naturatins;escutas-comprovam-existencia-de-fraude/50475/
} 
Paira, sobre a referida dispensa de licenciamento ambiental, iminente probabilidade de questionamento judicial local, a exigir especial atenção por parte dos atores do sistema de justiça.

\section{A IMPORTÂNCIA DA ARGUMENTAÇÃO: DIRETRIZES PARA O ENFRENTAMENTO JUDICIAL}

Conferir solução judicial para conflitos ambientais constitui tarefa de alta complexidade, por demandar sofisticada atividade argumentativa, sobretudo ante a força dos argumentos econômicos contrários aos princípios de proteção ambiental. Conforme alerta GUIMARÃES (1997 apud FREIRIA, 2011, p. 12). "as causas e implicações da crise ambiental revelam dimensões políticas, econômicas, institucionais, sociais e culturais, e seus efeitos transcendem as fronteiras nacionais".

Sem maiores dificuldades, revela-se a importância de que as decisões judiciais ambientais sejam dotadas de efetividade e eficácia, situação que coloca em evidência o importante papel, no exercício da atividade judicante, das teorias da argumentação jurídica, das quais, "resultan un abordaje constructivo y sustancial del derecho, describiéndolo y proponiendo herramientas que permiten evaluar la razonabilidad de las decisiones jurídicas y com ello colaborar - según nuestro entender - em la tarea de aproximar el fenómeno a la comunidad política que lo vive" ${ }^{4}$ (GRAJALES, 2014, p. 514).

No campo ambiental, a árdua missão da prestação jurisdicional, materializada pela decisão judicial, se agrega à necessidade de tornar efetivas as próprias políticas públicas de sustentabilidade, ou de afastar os atos de gestão pública que acarretem risco de danos ambientais, tarefa igualmente dificultosa. Como assinala Lanfredi (2002, p. 249), “o desafio posto ao Juiz diante da questão ecológica é tornar eficaz a aplicação das leis que regem a matéria”. Previsível, portanto, a fragilidade dos resultados quando o anteparo da atividade judicante não se mostrar adequado à magnitude do desafio.

Nota-se, no tema em exame, que a iniciativa governamental de eliminar a necessidade de licenciamento ambiental no território tocantinense constitui terreno fértil à argumentação jurídica, a qual, se bem estruturada, constituirá efetiva demonstração do grave erro cometido

4 "resultam numa abordagem construtiva e substancial do direito, descrevendo-o e propondo ferramentas que permitem avaliar a razoabilidade das decisões jurídicas e assim colaborar com a tarefa de aproximar o fenômeno à comunidade política que o vive." 
pela gestão pública tocantinense. Nesse contexto, serão tratados a seguir dos enfoques argumentativos essenciais para o enfrentamento judicial da dispensa de licenciamento ambiental introduzida no Estado do Tocantins pelo artigo 10 da Lei $n^{\circ} 2.713 / 13$.

\title{
3.1 Argumentação sob o enfoque das ciências do ambiente
}

Segundo dados catalogados pelo Instituto Brasileiro de Geografia e Estatística, o Estado do Tocantins tem a quase totalidade de seu território (91\%) ocupada pelo bioma Cerrado, segundo maior bioma da América do Sul, com extensão aproximada de 2.036.448 quilômetros quadrados (aproximadamente 23\% de todo o território brasileiro). O Ministério do Meio Ambiente descreve bioma como

\begin{abstract}
[...] um conjunto de tipos de vegetação que abrange grandes áreas contínuas, em escala regional, com flora e fauna similares, definida pelas condições físicas predominantes nas regiões. Esses aspectos climáticos, geográficos e litológicos (das rochas), por exemplo, fazem com que um bioma seja dotado de uma diversidade biológica singular, própria. No Brasil, os biomas existentes são (da maior extensão para a menor): a Amazônia, o Cerrado, a Mata Atlântica, a Caatinga, o Pampa e o Pantanal (PORTAL BRASIL, 2009, s/p).
\end{abstract}

O Cerrado ocupa também a totalidade do território do Distrito Federal, a quase totalidade de Goiás (97\%) e mais da metade do Maranhão (65\%), Mato Grosso do Sul (61\%) e de Minas Gerais (57\%). Em porções menores, é encontrado em outros seis Estados brasileiros. No Estado do Tocantins, compõe a área de transição com a Amazônia, circunstância que lhe confere especial importância para o equilíbrio ecológico entre os ecossistemas.

As três maiores bacias hidrográficas da América do Sul(Amazônica/ Tocantins, São Francisco e Prata) têm sua nascente no Cerrado, o que denota o elevado potencial aquífero, garantindo-lhe a denominação de berço das águas e do que resulta sua grande biodiversidade (LIMA, 2011).

Outra importante área de transição em solo tocantinense é a do Jalapão (transição entre os biomas Caatinga e Cerrado), região prioritária para a conservação do equilíbrio ecológico brasileiro (DOS SANTOS; ADORNO; SANTOS, 2008). A despeito disso, estudos indicam que apenas cerca de $20 \%$ do Cerrado ainda possui a vegetação nativa em estado relativamente intacto; 
[...] depois da Mata Atlântica, o Cerrado é o ecossistema brasileiro que mais alterações sofreu com a ocupação humana. Um dos impactos ambientais mais graves na região foi causado por garimpos, que contaminaram os rios com mercúrio e provocaram o assoreamento dos cursos de água (bloqueio por terra). A erosão causada pela atividade mineradora tem sido tão intensa que, em alguns casos, chegou até mesmo a impossibilitar a própria extração do ouro rio abaixo. Nos últimos anos, contudo, a expansão da agricultura e da pecuária representa o maior fator de risco para o Cerrado (WWF-Brasil, s/a)

Conforme divulgado pelo Governo Federal ${ }^{5}$, trata-se de um dos biomas brasileiros mais ameaçados, pois já perdeu quase metade de sua cobertura vegetal original; todo ano são desmatados mais de 14 mil $\mathrm{km}^{2}$ de área; queimadas e incêndios florestais têm relação direta com o desmatamento; 132 espécies da flora estão ameaçadas de extinção; a degradação da vegetação remanescente ameaça a qualidade dos recursos hídricos; já foram desmatados um total de $975,7 \mathrm{mil} \mathrm{km}^{2}$, quase metade da área total do bioma.

Dos dados oriundos das ciências do ambiente, nota-se que, com especial importância, atrelam-se ao contexto ambiental do Estado do Tocantins os princípios jurídico-ambientais da prevenção, precaução, responsabilidade e proibição de retrocesso, bases do desenvolvimento sustentável. Constituída está, sob este enfoque, argumentação suficiente à demonstração de que a dispensa de licenciamento ambiental às atividades rurais no Estado do Tocantins não apenas eleva a fragilidade do bioma cerrado, mas desconsidera sua importância para o equilíbrio ecológico global.

\subsection{Argumentação sob o enfoque constitucional}

O dispositivo legal em questão padece de flagrantes vícios de inconstitucionalidade, tanto no aspecto formal (vício constitucional de forma) quanto no aspecto material (vício constitucional de conteúdo). Frente ao princípio da hierarquia das normas e do dever de compatibilização de toda e qualquer lei à Constituição Federal, a argumentação jurídica acerca da invalidade do preceito legal em exame deve se iniciar pelo aspecto constitucional.

5 http://www.mma.gov.br/biomas/cerrado. acessado em 18/5/2018. 
A fim de privilegiar a didática, os defeitos formais (de estrutura) e materiais (de conteúdo) serão abordados separadamente a seguir.

\subsubsection{Inconstitucionalidade formal: ofensa ao artigo 24, VI, da Constituição da República}

Em primeiro plano, é de fácil constatação a inconstitucionalidade formal do artigo 10 da Lei 2.713, de 9 de maio de 2013, do Estado de Tocantins, já arguida perante o Supremo Tribunal Federal pelo Ministério Público Federal, nos autos da Ação Direta de Inconstitucionalidade $n^{\circ}$ 5312/TO. Segundo aduz o autor da ação, a Assembleia Legislativa local usurpou a competência atribuída à União para prover normas gerais de proteção ambiental (art. 24, VI, da Constituição Federal), extrapolando a permissão de normatização suplementar dada pelos parágrafos $1^{\circ}$ e $2^{\circ}$ do mesmo artigo 24.

Conforme o raciocino traçado na $\mathrm{ADI}$, ao criar exceção à obrigação de licenciamento ambiental, a lei estadual desrespeitou o princípio ambiental da precaução, situação que contraria o $\S 1^{\circ}$ do art. 225 da Constituição Federal (CF). Na petição inicial, argumenta-se, ainda, que apesar de a integração da agricultura, pecuária e silvicultura ter por objetivo a sustentabilidade e o baixo impacto ambiental, a denominação agrossilvipastoril não garante, por si só, ausência de dano ao meio ambiente, razão pela qual é indispensável o estudo prévio de impacto ambiental e o consequente licenciamento.

Tais constatações são inequívocas e, certamente, acarretarão a declaração da inconstitucionalidade do dispositivo legal pela Corte Suprema, pretensão que já conta com parecer favorável, anexado aos autos em 28 de janeiro de $2016^{6}$, exarado pelo Procurador-geral da República, segundo o qual não cabe à lei estadual decidir sobre a necessidade de licenciamento ambiental no caso de atividades conjuntas de lavouras, pastagens, florestas e a criação de animais.

Em sua manifestação nos autos do referido processo, o representante do parquet federal reafirma a competência da União para legislar sobre as normas gerais relativas às florestas, caça, pesca, fauna, conservação da natureza, defesa do solo e dos recursos naturais, proteção do meio ambiente e controle da poluição, cabendo aos estados federados regulamentar apenas normas específicas, sem ofensa à competência da União, estabelecida

6 portal.stf.jus.br/processos/downloadPeca.asp?id=308572468\&ext=.pdf $>$. acessado em 24/05/2019 
expressamente pela Constituição Federal e pela Política Nacional do Meio Ambiente, a qual estabelece competir ao Conselho Nacional do Meio Ambiente o estabelecimento de regras e critérios de licenciamento ambiental.

É clara, portanto, a inconstitucionalidade formal do artigo 10 da Lei Estadual, que instituiu a dispensa de licenciamento ambiental, por flagrante ofensa ao artigo 24, VI, da Constituição Federal.

\subsubsection{Inconstitucionalidade material: ofensa ao artigo 225 da Constituição da República}

No plano internacional, a matéria meio ambiente integra o ordenamento positivo de diversos países, na maioria das vezes em nível constitucional. Em reforço à proteção internacional, a Declaração Universal dos Direitos Humanos de 1948, somada à Declaração do Meio Ambiente (Estocolmo, 1972) e à Convenção sobre a Diversidade Biológica (Rio de Janeiro, 1992), posicionam o meio ambiente no rol dos direitos protegidos da humanidade.

No Brasil, a partir de 1988, o direito ao meio ambiente ecologicamente equilibrado (artigo 225) e a premissa de desenvolvimento econômico sustentável (artigo 170, VI) consagraram-se expressamente na ordem constitucional. Além da proteção expressa no âmbito constitucional, as questões ambientais estão também diretamente atreladas aos princípios fundamentais da cidadania e da dignidade da pessoa humana (artigo $1^{\circ}$, II e III) e aos direitos e garantias fundamentais (artigo $5^{\circ}$ - direito à vida; artigo $6^{\circ}$ - direito à saúde). É inequívoca, portanto, a proteção constitucional.

Conforme descrito, a importância do Bioma Cerrado para o equilíbrio ambiental encontra-se plenamente constatada no âmbito das ciências da natureza, por sua estratégica posição dentre os demais ecossistemas brasileiros, em especial a caatinga e a floresta amazônica, o que lhe confere papel fundamental de transição e integração ecológica. A exigência de licenciamento ambiental, existente no ordenamento legal tocantinense até sua revogação pela Lei $n^{\circ} 2.713 / 13$, desempenhava importante papel de controle na degradação do bioma Cerrado, contribuindo sobremaneira com a efetivação dos princípios ambientais da precaução e prevenção.

Logo, as constatações científicas acerca do funcionamento dos ecossistemas e o atual contexto brasileiro de constitucionalismo fraternal, 
voltado à qualidade de vida das presentes e futuras gerações, revelam claramente a inconstitucionalidade material da recente dispensa de licenciamento instituída no Estado do Tocantins. Além das regras da Política Nacional de Meio Ambiente, o novo programa ambiental tocantinense desrespeita frontalmente o princípio da proibição de retrocesso, ou de não regressão. Trata-se de princípio geral do Direito Ambiental, que visa à salvaguarda dos progressos obtidos para evitar ou limitar a deterioração do meio ambiente e

[...] a expressão de um dever de não regressão que se impõe à Administração [...] especificamente na seara do meio ambiente, entendemos que há distintos graus de proteção ambiental e que os avanços da legislação consistem em garantir, progressivamente, uma proteção a mais elevada possível, no interesse coletivo da Humanidade (BRASIL, 2012, p. 14).

O nada saudável cenário ecológico global e regional - sobretudo na situação atual de graves danos ambientais - denota o descaso da medida governamental tocantinense no que diz respeito à tutela ambiental local. É nítida a ofensa não apenas aos preceitos do artigo 225 da Constituição Federal, mas também aos princípios éticos que devem nortear a tônica de todas as ações humanas, especialmente na seara das políticas públicas, como a seguir se verá.

\subsection{Argumentação sob o enfoque da ética}

Em breves pinceladas, ética pode ser definida como "ciência do comportamento moral dos homens em sociedade" (VÁZQUEZ, 2004, p. 23). Na explanação de Aristóteles, mencionada por Siqueira Jr. (2012), a ética indica as disposições do ser humano perante a vida. $\mathrm{O}$ autor a conceitua como "a parte da filosofia que se preocupa com o agir humano, ou mais precisamente, o agir corretamente, tendo como objeto de estudo a moral" (p. 349). Logo, toda reflexão sobre ética passa por uma reflexão sobre valores, conforme assinala Reale acerca da imperatividade da guia valorativa da conduta escolhida, do ponto de vista de seus efeitos à coletividade:

[...] as normas éticas não envolvem apenas um juízo de valor sobre os comportamentos humanos, mas culminam na escolha de uma diretriz considerada obrigatória numa coletividade. Da tomada de posição axiológica resulta a imperatividade da via 
escolhida, a qual não representa assim mero resultado de uma decisão, arbitrária, mas é a expressão de um complexo processo de opções valorativas, no qual se acha, mais ou menos condicionado, o poder que decide (REALE, 1990, p. 33).

Sem embargo a visões diversas, é sedutora a ideia de Reale de que a verdadeira compreensão da juridicidade e da moralidade das condutas humanas depende da assunção do caráter obrigacional das normas éticas. Segundo Bittar (2013), ética corresponde ao exercício social de reciprocidade, respeito e responsabilidade. Com acurada sensibilidade, o autor pontua ser "na balança da ética que se devem pesar as diferenças de comportamento, para medir-lhes a utilidade, a finalidade, o direcionamento, as consequências, os mecanismos, os frutos...” (BITTAR, 2013, p. 25).

Assim como para os deveres, a preocupação da ética se volta também para os direitos, bifurcando-se em dois campos científicos: a deontologia como estudo dos deveres e a diceologia, estudo dos direitos (SIQUEIRA JR. 2012, p. 349). Ressaltando a grandeza do tema, Nalini (2008) conceitua:

O que designaria a ética seria não apenas uma moral, conjunto de regras próprias de uma cultura, mas uma verdadeira 'metamoral', uma doutrina situada além da moral. Daí a primazia da ética sobre a moral: a ética é desconstrutora e fundadora, enunciadora de princípios ou de fundamentos últimos (NALINI, 2008, p. 115).

A ética é, assim, o regulador da conduta humana, podendo-se afirmar que a humanidade possui seu acervo ético, formado pelo conjunto de ações que servem de referência e espelho para as futuras gerações. Constata-se que "todo processo de formação de uma identidade ética e de uma consciência ética para uma coletividade decorre de um princípio: a ação individual.” (BITTAR, 2013, p. 93). Não há, portanto, como desatrelar a ação humana da ética, especialmente no campo das atividades políticas, da gestão administrativa e da instituição de políticas públicas ambientais.

\subsection{1 Ética profissional dos agentes públicos e políticos}

Na esfera da atuação política, pela sobrelevada força e significado que carregam, de direcionamento de condutas, as ações de gestão pública ganham especial relevância. Daí a indispensável necessidade ética, além do dever legal e moral, de ser, a gestão pública, sempre norteada pelas 
máximas constitucionais. Com relevo, Bittar pontua que "gerir com responsabilidade é um dever jurídico-político, sem dúvida, mas, sobretudo, um dever ético, decorrente da própria confiabilidade depositada pelo eleitor sobre o eleito" (2013, p. 512). Conclui o autor, com sobriedade:

O que é de interesse de todos não pode estar à deriva, e muito menos ser conduzido ao sabor da vontade de um. Se a um ou a alguns é atribuído o mister de executar por muitos e em favor de muitos, significa que essa atribuição é um ato não de concessão de poderes, mas, sobretudo, de atribuição de deveres sociais. (BITTAR, 2013, p. 513)

A responsabilidade e a ética, desse modo, formam a linha mestra da conduta dos agentes públicos ou políticos, devendo ser, a proteção do interesse coletivo - e não de determinadas categorias ou grupos -, seu mister. Mas, a dispensa de licenciamento ambiental no Estado do Tocantins não se mostra atrelada a esses preceitos.

\subsection{2 Ética e o princípio responsabilidade}

Não há como identificar interesse coletivo que, em graduação valorativa, anteceda o da preservação da vida humana no planeta. Independente de fatores ideológicos, econômicos ou religiosos, um ambiente sadio que, do ponto de vista das condições naturais para a vida é pré-requisito para a existência digna de qualquer indivíduo ou o desenvolvimento de qualquer sociedade. Só se pode objetivar algo quando se está vivo, e a vida depende de determinadas condições naturais para ocorrer e se desenvolver, pois " [...] se levarmos em frente o modelo desenvolvimento até aqui adotados poderemos chegar a uma situação de irreversibilidade para a natureza e, por conseguinte, da vida humana [...] (MEDINA, P., 2011, p. 81)

Inegavelmente, as condições para a vida humana estão vinculadas à saúde do meio ambiente. Pode-se dizer, portanto, que ter um ambiente onde se possa viver é o valor primordial para que tudo mais possa ocorrer ou decorrer da vida humana, porque

A natureza é uma condição para a vida humana, pois a Terra põe instâncias para se construir em meio às conexões que evocam a proteção de que necessita o mundo. A Terra é mais que um planeta, é o espaço das realizações do mundo, como soma das experiências humanas na história, ou seja, aquilo que constitui a realidade, a condição humana. É dela, da Terra, que advém, desde sempre, as condições para viver e criar. Vivos, estamos permanentemente ligados a ela. (MEDINA, 2011, p. 81) 
Percebe-se, facilmente, que a ética e a responsabilidade estão, na relação homem-natureza, atreladas de maneira indissociável. Logo, a preservação do equilíbrio ecológico do planeta deve nortear toda e qualquer conduta humana. Nessa mesma vertente, a ampliação das dimensões da ética ao patamar global, refletida por JONAS (2006) ainda nos tempos de guerra fria, representou uma quebra de paradigmas e mostra-se, até hoje e talvez para um futuro distante e indeterminado, atualíssima.

Ao ponderar sobre os avanços tecnológicos, sobre a força das ações humanas e seus efeitos no planeta, JONAS (2006) passou a vislumbrar que um objeto de ordem inteiramente nova, nada menos do que a biosfera inteira do planeta, acresceu-se àquele pelo qual temos de ser responsáveis, pois sobre ela detemos poder. Considerou, portanto, que a diretriz kantiana "Aja de modo que tu também possas querer que a tua máxima se torne lei geral" merecia adequação para "Aja de modo a que os efeitos da tua ação sejam compatíveis com a permanência de uma autêntica vida humana sobre a Terra" (p. 48).

Indiscutivelmente, esse é o alicerce para toda e qualquer conduta humana. Nas palavras de Bauman (1997), "os deveres tendem a fazer os humanos iguais; a responsabilidade é o que os fazem indivíduos" (p. 66). Logo, é na perspectiva do princípio da responsabilidade que devem ser enfrentadas as questões relacionadas ao desenvolvimento econômico e social.

Novamente aqui se constata o alvedrio ao princípio da responsabilidade com a eliminação da necessidade de licenciamento ocorrida no território tocantinense.

\subsection{3 Ética e meio ambiente}

Atualmente, pode-se dizer que a preservação ecológica é o maior desafio da humanidade. O equilíbrio do meio ambiente, como condição da existência de vida humana na terra, sintetiza, conjuntamente, valores individuais e coletivos da mais alta magnitude.

Do ponto de vista dos fins a serem alcançados pelos Estados, especialmente o brasileiro, tendo em vista das diretrizes dos artigos 170 e 225 da Constituição Federal, o tema encontra bom enfoque na concepção transpersonalista, doutrina segundo a qual é possível conciliar elementos presentes isoladamente nas visões opostas individualista e coletivista (NADER, 2013). 
Nalini (2008) entrelaçando gestão pública e meio ambiente discorre sobre uma ética ecológica ou ética ambiental ponderando sobre a necessidade de se pensar no futuro, "e não no prazo ínfimo de uma gestão ou de um plano governamental" (p. 366). Pontifica o autor que "se os ataques à natureza procedem do homem, a ecologia é tema eminentemente ético" (p. 368/369).

No que diz respeito à atuação dos agentes públicos e políticos, a ética exige, especialmente no trato das questões atreladas ao desenvolvimento econômico e à preservação do meio ambiente, que os princípios e exigências constitucionais referentes aos bens e valores supramencionados, sejam sempre respeitados. Mais do que isso, devem ser elevados ao primeiro plano, sobretudo quando do exercício da atividade parlamentar (poder legislativo) ou da gestão pública (poder executivo) e o mesmo dever no campo da prestação jurisdicional (poder judiciário).

Há de se ter em mente que, "na atividade econômica, os fins não justificam os meios" (BITTAR, 2013, p. 122), e que "o homem não é dono da natureza; ele a recebeu por empréstimo e prestará contas pela sua malversação" (NALINI, 2008, p. 369). Atender, conjuntamente, os comandos constitucionais de preservação do equilíbrio ecológico do ambiente e de desenvolvimento econômico sustentável não se limita ao cumprimento de um dever positivado. No campo da ética, reflete postura responsável para com a preservação da vida humana. Possui, destarte, duplo valor. Em congruência com os postulados de Jonas acerca do princípio responsabilidade, Bittar (2013) apregoa, com razão, que "a aposta nos caminhos da ética é uma investidura na esperança" (p. 19). E assim deve ser.

\subsection{Argumentação sob o enfoque do Direito Penal}

De maneira resumida, sem pretensão à exposição de postura doutrinária ou crítica acerca do Direito Penal, pode-se dizer que, em suas várias fases evolutivas, este ramo das ciências jurídicas sempre se norteou pela função protetiva de bens jurídicos e valores instituídos pelas sociedades, muito embora não se possa olvidar que tal proteção exerce, por vezes, função meramente simbólica ou, na visão de muitos, inócua.

É crescente, modernamente, a defesa do minimalismo penal, ou do direito penal mínimo, segundo o qual a sanção penal somente se justificaria em casos de delitos graves, sob argumento de que a punição não contribui 
de maneira eficaz com a redução da criminalidade.

Em contraposição, há os que defendem a atuação máxima do direito penal, como forma de eliminação total da impunidade. Na seara ambiental, é frequente a defesa da necessidade da tutela penal. Nessa linha, a doutrina brasileira especializada, em sua quase totalidade, ressalta:

A maioria dos países da Europa pune a pessoa física e jurídica que lesa o meio ambiente, não só administrativa ou civil, mas também penalmente. Nas esferas administrativa e civil, a proteção ao meio ambiente não tem sido eficaz. Na esfera administrativas, das multas aplicadas pelo IBAMA, em 1997, somente seis por cento foram recolhidas aos cofres públicos e, na esfera civil, nem todas as ações civis públicas têm sido coroadas de êxito, especialmente pela demora no seu trâmite. Por isso, a necessidade da tutela penal, tendo-se em vista seu efeito intimidativo e educativo e não só repressivo. Trata-se de uma prevenção geral e especial. (...) Nos dias presentes, a tendência no mundo moderno é responsabilizar penalmente a pessoa física e jurídica que cometa crimes contra o meio ambiente. (SIRVINSKAS, 2011, p. 47)

Nesse mesmo sentido, Freitas (2012), com propriedade, explana que a luta na defesa do meio ambiente tem encontrado no Direito Penal um de seus mais significativos instrumentos. Após constatar que as sanções civis e administrativas não se mostram suficientes para a repressão das agressões ambientais.

Evidentemente, não seria necessário criminalizar condutas se houvesse, por parte da sociedade, a compreensão da importância de preservar o meio ambiente, ética ambiental. A realidade, como lembra José Renato Nalini, é que 'A proteção à natureza independe de educação, riqueza ou mesmo religião. Em todos os estamentos há infratores. Desde as grandes madeireiras, sem pátria e sem lei, aos despossuídos que dizimam áreas próximas aos mananciais’. (FREITAS, p. 33)

Reconhecendo a forte tendência do princípio da intervenção mínima, especialmente nos países latinos, Freitas (2012) se opõe à aplicação da tese da ultima ratio à seara ambiental, lembrando que a importância da tutela penal vem sendo destacada internacionalmente desde há muito. O autor relembra que no XII Congresso Internacional de Direito Penal ocorrido em Varsóvia em 1975, foi aprovada a resolução de tratar como delitos contra a humanidade e submeter a grave repressão, as agressões 
ao meio ambiente. $\mathrm{O}$ autor denota, ainda, o mesmo pensamento constante na doutrina portuguesa de Anabela Miranda Rodrigues, segundo a qual "dignidade penal e necessidade de tutela penal são categorias que intervêm a legitimar a intervenção penal, e não se vê razão para que não intervenham aqui." (op. cit., p. 35).

Sem oposição ou defesa direta ao Direito Penal mínimo ou máximo, Oliveira (2012) apresenta panorama histórico da pena na tradição jurídica discorrendo desde a punição como sanção ético-moral-religiosa até a construção instrumental dos fins da pena, na defesa da racionalidade. Sua tese argumenta acerca da aplicabilidade das concepções de Habermas à seara do Direito Penal. O autor ilumina o raciocínio favorável à constatação da legitimidade das penas:

Não obstante haver Zaffaroni acertadamente denunciado a ilusão justificadora (que é promovida pela racionalidade instrumental), equivoca-se ao dizer que as penas não podem encontrar legitimidade. Podem sim, mas não numa perspectiva instrumental, e sim numa perspectiva comunicativa, encontrando repouso no consenso racionalmente motivado dos participantes, orientador das ações individuais dos destinatários sociais da norma. (OLIVEIRA, p. 121)

O consenso verdadeiro preconizado por Habermas, concebido sempre numa situação de fala ideal, pressupõe, em síntese, um princípio de veracidade, ou de sinceridade, decorrente da validade daquilo que se defende, sem engano ou intimidação dos interlocutores, na hipótese em estudo, os destinatários da norma penal. Depende, por isso, de um valor universal, ou ao menos universalizável.

Na seara ambiental, a defesa do equilíbrio ecológico do planeta único meio eficaz, no atual cenário científico, de preservação da espécie humana - é dotada de uma pretensão muito forte de validade (ou validez). Espera-se, com isso, a plena viabilidade da ação comunicativa de normas penais severas quando se tratar de crimes ambientais, ponderadas, é claro, na medida do dano resultante da conduta lesiva ao meio ambiente, como sugere Santos (1996):

Refletindo por este caminho, entendemos que a tipificação do crime ecológico e sua respectiva pena devem obedecer a dois caminhos: um vertical e outro horizontal. No primeiro, devemos ter um sistema punitivo, em que a pena se aprofunda de acordo com a gravidade do ato ilícito praticado, segundo este aprofundamento de 
forma cumulativa. (...) Desta forma, teríamos um aumento da dosagem da pena, paralelamente ao aprofundamento da gravidade do delito. (SANTOS, 1996 p. 101102)

As soluções que o Direito Penal apresenta devem sempre observar aspectos de política criminal, quais sejam, utilidade social da punição e intervenção social preventiva. Afigura-se viável, portanto, não apenas a tutela penal, mas a instituição de penas pecuniárias realmente elevadas, além da prestação de serviços à comunidade visando à restauração e preservação ambiental, no lugar de privação de liberdade.

Há de se admitir que a situação ideal de fala pode, de fato, ser algo inalcançável. Mesmo na visão de Habermas, a humanidade não está preparada para o consenso. A busca de consenso verdadeiro, embora possa ser ideal utópico, deve ser perseguida. Mas a aproximação do consenso verdadeiro se dá na medida em que evolui a comprovação empírica daquilo que se examina.

As comprovações científicas, por sua vez, são sempre provisórias, sujeitando-se a novas descobertas. Suas premissas são, por isso, fruto da permanente abertura à discussão. Por isso, os valores instituídos por constatações científicas são dotados de transitoriedade, inerente ao dinamismo próprio da condição humana.

Assim, no plano das atuais constatações ambientais, dentre as quais a comprovação científica do irreversível abalo ao equilíbrio ecológico do planeta, a necessidade de tutela rígida alcança uma pretensão muito forte de validade. Ou seja, em curto prazo, as descobertas científicas mais otimistas não serão suficientes para suplantar a necessidade de proteção ambiental. Alcança-se, com isso, uma verdade científica de caráter quase perpétuo, ou imutável: o risco de extinção da espécie humana. Tal verdade cria a franca possibilidade de fala ideal. Afinal de contas, qual raciocínio ou valor poderia sobrepor-se à garantia de continuidade da vida no planeta?

A despeito da validade desse interesse universalizável (vida sustentável, preservação da espécie humana), nem todos direcionam seu olhar e suas condutas às gerações futuras. A situação é ainda mais grave quando tal comportamento advém do poder público, ou dos gestores públicos, como no caso em exame, pois

As assistências próprias do dever parental ou governamental se expressam de modo global, não podendo sofrer descontinuidade. Essas responsabilidades não cessam e 
não há o fim de uma obrigação. O que está em jogo é a existência inteira da pessoa ou da identidade social a ser garantida, no caso, a governamental. (MEDINA P. , 2011, p. 142)

Para estes - que em tese não aderem ao consenso sobre a necessidade da tutela penal do meio ambiente - resta a ação estratégica da norma e seu caráter intimidador e punitivo, já que o bem tutelado é, em última análise, a preservação da própria espécie humana, valor que se sobrepõe à vida individualmente considerada, uma vez que os efeitos do poder geram o conteúdo do dever, em resposta ao que acontece. Pode-se dizer que, se os efeitos colocam em risco as condições da existência humana, é razoável propor que, durante certo tempo e sob certas condições, as aspirações mais particulares, a fruição e a ética orientada à boa vontade serão substituídas por deveres impostos a nós mesmos, nascidos da vontade como elemento de autocontrole do nosso próprio poder conscientemente exercido (JONAS, 2006).

Pode-se dizer, com isso, que a preservação do equilíbrio ecológico do meio ambiente é um interesse universalizável, de modo que, para a defesa da vida - se a humanidade não alcançar a plenitude do consenso (cenário de fala ideal) - justificada está a ação estratégica da tutela penal ambiental rígida e severa.

\section{CONCLUSÕES}

Recentes constatações científicas avalizadas pela Organização das Nações Unidas demonstram a iminência de vivenciarmos uma catástrofe ambiental de proporção global ainda neste século, em decorrência das alterações climáticas derivadas de ações humanas, em especial a queima de combustíveis fósseis e o desmatamento. $\mathrm{Na}$ visão de boa parte dos cientistas, o equilíbrio ecológico planetário já se encontra irreversivelmente abalado, o que pode conduzir, na hipótese mais drástica (na perspectiva antropocêntrica), à extinção da espécie humana.

A reversibilidade desse cenário exige conhecimento e ampla conscientização acerca das condutas humanas lesivas ao ambiente, o que perpassa pelas dificuldades inerentes à interdisciplinaridade das questões envolvidas. Na sociedade atual, os valores humanos guardam ligação direta com o desenvolvimento econômico. Não obstante, a garantia da vida humana no planeta depende do equilíbrio ecológico global, o que torna 
inequívoca a premissa de que a manutenção desse equilíbrio deve guiar toda e qualquer conduta humana, de toda e qualquer comunidade, estado ou nação, independente do regime político ou econômico adotado, das crenças ou dos ideais almejados pelos povos, de ordens jurídicas internas ou de tratados e convenções internacionais.

É indispensável que, na atividade política e econômica, especialmente na gestão pública, a ordem de valores constitucionais seja respeitada $^{7}$. A recente alteração legislativa tocantinense - dispensa do licenciamento ambiental para atividades agrossilvipastoris - denota que a preocupação dos atuais gestores continua centrada apenas no acesso à riqueza, a despeito da necessidade de deslocamento do eixo central da conduta administrativa na direção da responsabilidade e futuro.

$\mathrm{O}$ que de fato caracteriza a responsabilidade total por uma vida, seja ela individual (parental) como coletiva (governamental), é sua ocupação com o futuro, mais do que o presente, aspecto inteiramente negligenciado pela edição da lei em pauta. O futuro é a existência inteira, mais além da influência direta do responsável e, por isso mesmo, além do cálculo concreto e singular voltado para as necessidades mais próximas que se contam com o tempo de uma biografia. $\mathrm{O}$ futuro escapa à previsão tanto por causa de suas variáveis do desconhecido que reunidas constituem as circunstâncias objetivas, quanto pela espontaneidade e liberdade próprias da vida.

Os agentes políticos e públicos locais agiram na contramão da diretriz constitucional de desenvolvimento sustentável. Deixaram em segundo plano o necessário e perfeitamente possível equilíbrio entre desenvolvimento econômico e preservação, que demanda considerar os efeitos pelos quais o responsável já não poderá responder. Vislumbram-se ofensas a direitos humanos, e os danos podem ser irreversíveis. Dispensar o licenciamento ambiental configura perigoso retrocesso, ofensivo aos deveres de prevenção, que implica o dever de evitar tudo aquilo que sabidamente é danoso ao meio ambiente e de precaução qual seja de proibição a ações temerárias, quando o resultado da intervenção humana é ainda desconhecida, bem como ao dever de equidade intergeracional, os quais compõem os princípios da responsabilidade e integram os pilares do desenvolvimento sustentável.

7 "Em suma, quando o econômico está a reger a orquestra, a sinfonia é a do individualismo e não a do coletivismo. Desmantelar essa ideologia e desmascarar suas armadilhas é o dever de toda ética." (BITTAR, Eduardo C. B. Curso de Ética Jurídica, 2013, p.124). 
Provocada, a atuação judicial tem à sua disposição, no campo da ética, do direito penal e da proteção constitucional aos direitos fundamentais, argumentação jurídica sólida o suficiente para convencer sobre o equívoco da administração pública tocantinense ao promover, com a edição da Lei Estadual no 2.713, de 9 de maio de 2013, a dispensa da necessidade de licenciamento ambiental para o desenvolvimento de atividades agrossilvipastoris.

\section{REFERÊNCIAS}

AMEAÇAS ao cerrado. www-brasil. Disponível em: < http://www.wwf. org.br/natureza_brasileira/questoes_ambientais/biomas/bioma_cerrado/ bioma_cerrado_ameacas/>. Acesso em: 17 maio 2018.

BAUMAN, Zygmunt. Ética pós-moderna. São Paulo: Paulus, 1997.

BEYRUTH, Zuleika. Aprendendo sobre qualidade de vida com as águas poluídas da cidade de São Paulo. São Paulo: Revista USP, 2006.

BRASIL. Lei Federal nº 1.985, de 29 de janeiro de 1940. Código de Minas BRASIL. Lei Federal no 4.504, de 30 de novembro de 1964 (Estatuto da Terra);

BRASIL. Lei Federal n ${ }^{\circ}$ 4.771, de 15 de setembro de 1965. Institui o novo Código Florestal.

BRASIL. Lei Federal n ${ }^{0}$ 5.197, de 3 de janeiro de 1967. Dispõe sobre a proteção à fauna e dá outras providências.

BRASIL. Decreto-lei n $^{\circ} 221$ de 28 de fevereiro de1967. Dispõe sôbre a proteção e estímulos à pesca e dá outras providências.

BRASIL. Decreto-lei no 227 de 28 de fevereiro de 1967. Dá nova redação ao Decreto-lei no 1.985 , de 29 de janeiro de 1940.

BRASIL. Decreto-lei $\mathrm{n}^{\circ} 289$ de 28 de fevereiro de 1967. Cria o Instituto Brasileiro de Desenvolvimento Florestal.

BRASIL. Decreto ${ }^{\circ} 73.030$, de 30 de Outubro de 1973 Cria, no âmbito do Ministério do Interior, a Secretaria Especial do Meio Ambiente - SEMA. 
BRASIL. Lei Federal n ${ }^{\circ}$ 6.938/81, de 31 de agosto de 1981 que dispõe sobre a Política Nacional do Meio Ambiente, seus fins e mecanismos de formulação e aplicação.

BRASIL. Supremo Tribunal Federal. ADI 3540 MC, Rel. Min. CELSO DE MELLO, Tribunal Pleno, julgado em 01/09/2005, DJ 3/2/2006, p.14. Disponível em: , http://www.jusbrasil.com.br/jurisprudencia/ busca?q=ADI+3540+MC>. Acesso: 17 maio 2018

BRASIL. Constituição (1988). Constituição da República Federativa do Brasil. Brasília, DF: Senado Federal: Centro Gráfico, 1988.

BRASIL. Senado Federal. Comissão de Meio Ambiente, Defesa do Consumidor e Fiscalização e Controle. Princípio da Proibição de retrocesso ambiental. Brasília: DF, 2012. Disponível em: < http:/www.mma.gov. br/port/conama/processos/93127174/Voto_APROMAC_ANEXO.pdf $>$. Acesso em: 18 maio 2018.

BITTAR, Eduardo C. B. Curso de ética jurídica: ética geral e profissional. $10^{\mathrm{a}}$ ed. São Paulo: Saraiva, 2013.

CARRILlO, Carlos Alberto. Memórias da justiça brasileira. Salvador: Tribunal de Justiça do Estado da Bahia/Gerência de Impressões e Publicações, 2003.

DOS SANTOS, Eliane Marques; ADORNO Lúcio Flavo Marini; SANTOS, Eduardo Ribeiro dos. As fitofisionomias da Rodovia TO-030 no trecho da APA Jalapão ao Município de São Félix do Tocantins-TO. II SIMPÓSIO INTERNACIONAL SAVANAS TROPICAIS. 2008. Disponível em: $<$ http://simposio.cpac.embrapa.br/simposio_pc210/trabalhos_pdf/00134_ trab1_ap.pdf $>$. Acesso em: 17 maio 2018.

FREITAS, Juarez. Sustentabilidade: direito ao futuro. Belo Horizonte: Fórum, 2012.

GRAJALES, Amós A. Argumentación jurídica. Buenos Aires: Astrea, 2014

JONAS, Hans. O princípio responsabilidade: ensaio de uma ética para a civilização tecnológica. Rio de Janeiro: Contraponto: Ed. PUC-Rio, 2006. 
LAPA, J. R. A. A Bahia e a carreira da Índia. São Paulo: Editora da Unicamp, 2000.

LANFREDI, Geraldo Ferreira. Política ambiental: busca de efetividade de seus instrumentos. São Paulo: Editora Revista dos Tribunais, 2002.

LIMA, Jorge Enoch Furquim Werneck. Situação e perspectivas sobre as águas do cerrado. São Paulo: Ciência e Cultura, 2011.

LOVELOCK, James. A vingança de Gaia. Rio de Janeiro: Intrínseca, 2006.

MAGALHÃES, Juraci Perez. A Evolução do Direito Ambiental no Brasil. São Paulo: Oliveira Mendes, 2002.

MEDINA, Patrícia. A relação homem natureza, a fenomenologia do cuidar e a dimensão formativa. 2011. $166 \mathrm{f}$. Tese (Doutorado) - Curso de Faculdade de Educação, Programa de Doutorado em Educação, Universidade Federal de Goias, Goiania, 2011. Disponível em: <https://repositorio.bc.ufg.br/ tede/handle/tde/1125>. Acesso em: 18 maio 2018.

MENDONÇA, M. C. de. Raízes da formação administrativa do Brasil. Rio de Janeiro: Instituto Histórico e Geográfico Brasileiro: Conselho Federal de Cultura, 1972.

NADER, Paulo. Introdução ao estudo do direito. $35^{\mathrm{a}}$ ed. Rio de Janeiro: Forense, 2013.

NALINI, José Renato. Filosofia e ética jurídica. São Paulo: Editora Revista dos Tribunais, 2008.

OLIVEIRA, Tarsis Barreto. Pena e racionalidade. Rio de Janeiro: Lumen Juris, 2012.

ORDENAÇÕES Afonsinas. Instituto de História e Teoria das Ideais da Faculdade de Letras. Universidade de Coimbra. Portugal. Disponível em: $<$ http://www1.ci.uc.pt/ihti/proj/afonsinas/15ind.htm>. Acesso em: 18 maio 2018.

PORTAL BRASIL, 2009, s/p. Disponível em: <http://www.brasil.gov.br/ meio-ambiente/2009/10/biomas-brasileiros>. Acesso em: 18 maio 2018. 
REALE, Miguel. Lições preliminares de direito. $17^{\mathrm{a}}$ ed. São Paulo: Saraiva, 1990.

SANTOS, Pedro Sérgio dos. Crime ecológico: da filosofia ao direito. Goiânia: Editora da UFG, 1996.

SIQUEIRA JR., Paulo Hamilton. Teoria do Direito. $3^{\mathrm{a}}$ ed. São Paulo: Saraiva, 2012.

SIRVINSKAS, Luis Paulo. Tutela penal do meio ambiente. São Paulo: Saraiva, 2011

TOCANTINS. Lei Estadual $n^{\circ}$ 261, de 20 de fevereiro de 1991. Institui a Política Estadual de Meio Ambiente.

TOCANTINS. Lei Estadual $n^{\circ} 2.713$, de 9 de maio de 2013. Disponível em: < http://dri.sefaz.to.gov.br/legislacao/ntributaria/Leis/Lei2.713.13. htm >. Acesso em: 18 maio 2018.

VÁZQUEZ, Adolfo Sanchez. Ética. $25^{\mathrm{a}}$ ed. Rio de Janeiro: Civilização Brasileira, 2004.

Artigo recebido em: 25/07/2018.

Artigo aceito em: 12/02/2019.

\section{Como citar este artigo (ABNT):}

VAMPRÉ, S.; MEDINA, P. Dispensa de licenciamento ambiental para atividades rurais no estado do Tocantins: suporte teórico para um discurso argumentativo. Veredas do Direito, Belo Horizonte, v. 16, n. 34, p. 177204, jan./abr. 2019. Disponível em: $<$ http://www.domhelder.edu.br/revista/ index.php/veredas/article/view/1254>. Acesso em: dia mês. ano. 